\title{
DIETARY SUPPLEMENTATION OF VITAMIN C, L-ASCORBATE 2-TRIPHOSPHATE CALCIUM (LATP-Ca) ON OOCYTE DEVELOPMENT OF MAJOR CARP ROHU (LABEO ROHITA) REARED IN A NATURAL CONCRETE POND
}

\author{
Shyam Narayan Labh \\ Department of Zoology \\ Amrit Science Campus, Tribhuvan University, Kathmandu, Nepal \\ Email: snlabh@gmail.com
}

\begin{abstract}
The aim of this study was to evaluate the effect of vitamin C L-ascorbate 2-triphosphate (LATP-Ca) on Indian major carp rohu (Labeo rohita) (Hamilton) during intensive aquaculture. Rohu were fed with vitamin $C$ (LATP-Ca) supplementation at doses of $D_{1}$ (control) and $D_{2}(500 \mathrm{mg} / \mathrm{kg})$ diet for 10 weeks. The effects were assessed by comparing the treated groups of fish to that of control group. Vitamin C (LATP-Ca) supplementation exerted significant $(P<0.05)$ effects on oocyte development of rohu (Labeo rohita). A number of distinct developmental stages of oocyte can be delineated and oocyte growth in major carp rohu (Labeo rohita) found in two distinct phases; primary growth phase (PGP) and the secondary growth phase (SGP). In PGP, oogonia, chromatin nucleolus, early and peri nucleolus stage oocyte with Balbiani's vitelline body were observed while two types of inclusions, lipid and protein, respectively were formed during vitellogenesis in the SGP. SGP development was found for a short period of time as compared to PGP. Similarly, development of oocyte was very poor in fish fed with controlled diet.
\end{abstract}

Key words: Major carp, Labeo rohita, vitamin C, histology, oocyte development.

\section{INTRODUCTION}

Morphology, biochemistry and physiology of gonads have been described by a large number of workers in different groups of fishes. Ovaries are not only responsible to produce eggs but also synthesize and secrete hormones of different kinds that have a far reaching effects on the reproductive biology and behavior of the fish. Oogenesis starts from simple proliferation of oogonia up to the formation of mature oocyte and consequently ovulation after final maturation. During this process, size of oocyte increases many folds and this is mainly due to accumulation of yolk granules which are formed in liver under the influence of a specific steroid hormone, 17ß-estradiol (Wallace and Selman 1981) and migrate to oocyte through blood (Wallace 1978). Oocyte development in teleosts has been reviewed by Wallace and Selman (1981), de Vlaming (1983), Nagahama (1983), Guraya (1986), and West (1990). Yamamoto et al. (1965) divided the oocyte development of rainbow trout into eight stages which includes chromatin nucleolus stage, perinucleolus stage (subdivided into early and late stage), oil droplet stage, primary 
yolk stage, secondary yolk stage, tertiary yolk stage, and maturation stages. Shrestha (1980) described the ovarian cycle of Noemacheilus beavani and divided it into seven distinct phases. Sen et al. (2002) divided the development stages of Labeo rohita (collected from rivers of West Bengal, India) into seven different stages as primary growth phase, perinucleolar stage, previtellogenic or yolk vesicle stage, vitellogenic stage post-vitellogenic stage, germinal vesicle break down stage, and spawning stage.

Several criteria have been employed for staging the process of oocyte development. These criteria are size, amount and distribution of various cell inclusions (Nagahama 1983). However, it is now generally recognised that oocyte growth occurs in two distinct phases including all these oocyte development stages. These phases are the primary growth phase (PGP) and the secondary growth phase (SGP) (Tokarz 1978, Khoo 1979). The primary growth phase is variously named as previtellogenesis (Raven 1961), the first growth phase (Jorgensen 1974, Khoo 1979), or the primary growth phase (Wallace and Selman 1981). The PGP in teleosts involves the increase in size of the primary oocytes with some nuclear changes, and shows little variation between species (Tokarz 1978, Wallace and Selman 1981, de Vlaming 1983, Guraya 1986). The secondary growth phase (SGP) of oocyte is a gonadotrophin-dependent phase. The enlargement of the oocyte, attributable mainly to the accumulation of yolk (vitellogenesis) occurs in this phase (Nagahama 1983). Oocyte development might be species specific with the size, amount and distribution of various cell inclusions or formation order.

The oocytes are expelled into the ovarian cavity or peritoneal cavity, a process known as ovulation. The follicular layers that remain behind in the ovary are known as Post-ovulatory follicle (POF). The entire process or at least part of it is hormone dependent (Lone et al. 2001, 2008).
However, final oocyte maturation and ovulation are not always associated because oocyte of most teleosts do not undergo ovulation following steroid maturation in vitro (Narimatsu et al. 2007).

Vitamin C is an essential vitamin for normal physiological functions in animals including fish (Lim and Lovell 1978). Most teleosts are unable to synthesize ascorbic acid due to the lack of 1gulonolactone oxidase that is responsible for synthesis of vitamin C de novo (Wilson 1973, Fracalossi et al. 2001). Therefore; an exogenous source of vitamin $\mathrm{C}$ is required in fish diets. Inadequate supply of dietary vitamin $\mathrm{C}$ usually results in a number of deficiency signs such as spinal deformation, impaired collagen formation, internal haemorrhaging and retarded growth (Halver et al. 1969, Al-Amoudi et al. 1992, Gouillou-Coustans et al. 1998). The requirement of vitamin $\mathrm{C}$ varies to some degree, with fish species, size, diet and experimental conditions. Thus, the role of vitamin $\mathrm{C}$ on oocyte development is much important but, information on carp is very limited and Labeo rohita, rohu is one of the Indian major carp. Its high commercial value makes it a promising aquaculture species in the future. Therefore, the purpose of the present study was to determine oocyte development using histological techniques of major carp rohu (Labeo rohita) during intensive aquaculture.

\section{MATERIALS AND METHODS}

\section{Fish collection and experimentation}

Labeo rohita (rohu) is a major carp and an annual breeder. Based on observations of wild fish, it attains maturity in the end of second year of life (Jhingran and Pullin 1985). Thus, one year old (mean weight $39.56 \pm 0.25 \mathrm{~g} /$ fish) rohu Labeo rohita $(\mathrm{H})$ used in the present study were obtained to the Aqua Research Lab, University of Delhi, India from a commercially well managed Jahangirpuri fish farm, located some $14 \mathrm{~km}$ from the research lab. Rohu were kept in outdoor 
conditions, acclimatized for 7 days and cultured 34 fishes/tank in rectangular cemented tanks (500 1) under two feeding regimes. Two practical (artificial) diets (protein 40\%) containing two doses 0 and $500 \mathrm{mg} \mathrm{kg}^{-1}$ of vitamin C, L-ascorbate 2- triphosphate Calcium (HiMedia, India) were formulated along with other ingredients viz., fish meal, wheat flour and cod liver oil (Labh and Chakrabarti 2011). In the first group, fish were fed without incorporation of vitamin C (LATP Ca) in the artificial diet served as control $\left(\mathrm{D}_{1}\right)$ and the second group of fish were fed with incorporation of vitamin C (LATP Ca) in the artificial diet, which served as high level $\left(D_{2}\right)$. Fish were fed twice daily at $9.00 \mathrm{am}$ and $6.00 \mathrm{pm}$ at the rate of $3 \%$ of body weight. Three replicates were used for each feeding scheme. Water temperature, $\mathrm{pH}$ and dissolved oxygen level were recorded weekly throughout the study period. The duration of experiment was 10 weeks and then the fishes were harvested.

\section{Experimental sampling}

At the time of sampling, fish were removed from the cemented tank one by one with a scoop net and immediately placed in a water tank containing clove oil (5 ppm) dissolved in absolute alcohol (Merck, Germany) in a ratio of 2:5 (Berka 1986) and allowed to stay for 3-5 minutes. The time period was changed according to weight and length of fish.

\section{Morphological and biochemical parameters}

Before dissection and removal of gonads total body weight to the nearest gram ( $\mathrm{g}$ ) and total body length, standard body length and body depth (at the start of the dorsal fin level) to the nearest $\mathrm{mm}$ were recorded. The specific growth rate (SGR) was calculated using the formula: $\mathrm{SGR}=100 \times(\mathrm{InWt}-$ InWi)/t, where Wi and $\mathrm{Wt}$ were the initial and final body weights and $\mathrm{t}$ time in days. Vitamin $\mathrm{C}$ contents in oogonia were assayed (Dabrowski and Hinterleitner 1989).

\section{Dissection and removal of gonads}

After measurements, an incision was made on ventral side of the abdomen from posterior to interior most tip of the fish with a sharp scalpel and a bone cutter. Ovaries were found attached on the lower side of the swim bladder in the abdominal cavity. Features like colour, position of gonadal ducts and any abnormality, if present, were noted. Photographs of the ovaries were taken in situ and then were separated carefully, then after their size and weight were recorded.

\section{Histological studies}

Whole ovary samples of immature and mature fishes for histological studies were taken and fixed in $10 \%$ buffered formalin (4\% formaldehyde in phosphate buffer) until processed for histological examinations. Samples were trimmed to approximately $1 \mathrm{~cm}^{3}$ and loaded to plastic tissue cassettes. The sample loaded cassettes were then processed for routine histology. The samples were first passed through different grades of ethyl alcohol ranging from $30-100 \%$ for dehydration and then cleared in two changes of xylene. The tissues were finally taken to embedding centre, transferred to molten wax and xylene in the ratio of 70:30 and in the last changed to molten wax for $4 \mathrm{~h}$ for impregnation of wax. The wax embedded tissues, attached to cassettes, were finally trimmed for microtomy. The sections were floated in warm water $37-40^{\circ} \mathrm{C}$ for stretching. The stretched sections were placed on glass slides, and put on a hot plate overnight for drying. Gill' haematoxylin and eosin staining method was used for this study (Gerrits 1990). The sections were stained with Harris hematoxylin and eosin and mounted with DPX. The photomicrography was done on LEICA PM-5000 microscope with digital camera.

\section{Statistical Analyses of the data}

To understand the significant difference between diet, the data obtained were analyzed statistically with One-way ANOVA followed by 
Duncan's Multiple Range Test at $P<0.05$ significance level using SPSS version 15.

\section{RESULTS}

Cent percent survival of carp was recorded in all the treatments. The final average weight of fish was significantly $(P<0.05)$ higher in the carp fed with diet $D_{2}$ as compared to diet $D_{1}$. The final average weight was $13.6 \%$ higher in the fish fed with $\mathrm{D}_{2}$ diet compared to control $\left(\mathrm{D}_{1}\right)$ diet fed fish. Vitamin $C$ level was significantly $(P<0.05)$ higher in fish fed with $\mathrm{D}_{2}$ compared to others regardless of tissues (Table 1). Significant changes were observed in the oocyte of treated fish compared to the control one. Water temperature ranged from 27.8 to $31.3^{\circ} \mathrm{C}, \mathrm{pH}$ ranged from 7.4 to 7.8 and dissolved oxygen level ranged from 6.7 to $7.3 \mathrm{mg} / \mathrm{l}$ throughout the study period.

\section{Gonad weight, length and width}

The two lobes of the ovary are separate in the beginning, however, as they grow, the lobes come together and an oviduct is formed. The weight of gonad $(33.11 \pm 2.06 \mathrm{~g})$ was the lowest in the stocking fish at the beginning of the experiment, $97.38 \pm 5.14 \mathrm{~g}$ in the $\mathrm{D}_{1}$ diet fed fish, while the highest value $(187.8 \pm 23.02 \mathrm{~g})$ was recorded at the end of the experiment in gonad of $\mathrm{D}_{2}$ diet fed fish (Figs. 1, 2 and 3). The ovarian width followed ovarian length and weight and was minimum in $\mathrm{D}_{1}$ $(5.702 \pm 0.09 \mathrm{~cm})$ while maximum values $(9.45 \pm$ $0.15 \mathrm{~cm}$ ) were in $\mathrm{D}_{2}$ diet fed fish.

Table 1. Average weight (g), specific growth rate (SGR), Vitamin $C$ concentrations in oogonia ( $\mu \mathrm{g} \mathrm{mg}^{-1}$ ) of rohu (Labeo rohita) cultured under two different feeding regimes.

\begin{tabular}{lcc}
\hline Parameters & $\begin{array}{c}\mathbf{D}_{1} \text { (Control } \\
\text { diet) }\end{array}$ & $\begin{array}{c}\mathbf{D}_{2} \text { (Vitamin } \\
\text { C added diet) }\end{array}$ \\
\hline Average Weight & $42.27 \pm 0.17$ & $49.32 \pm 0.13$ \\
SGR & $0.069 \pm 0.012$ & $0.236 \pm 0.08$ \\
Vitamin C in Oogonia & $159.81 \pm 24.2$ & $375.64 \pm 21.52$ \\
\hline
\end{tabular}

\section{Histological studies of the gonads}

In major carp rohu (Labeo rohita) abundant oogonia were observed in the different stage of ovary development (Fig. 4). They occur in nests of small rounded cells $(6.02 \pm 2.55 \mu)$ with a very high nucleus (Fig. 5) in the $\mathrm{D}_{1}$ diet fed fish while in the fish fed with $\mathrm{D}_{2}$ diet oogonial proliferation in newly formed primary oocytes $(23.33 \pm 6.05 \mu)$ and early perinucleolus stage of oocyte $(39 \pm 3.39 \mu)$ developed. Zona radiata and protein droplets observed in fully grown treated fish (Fig. 6).
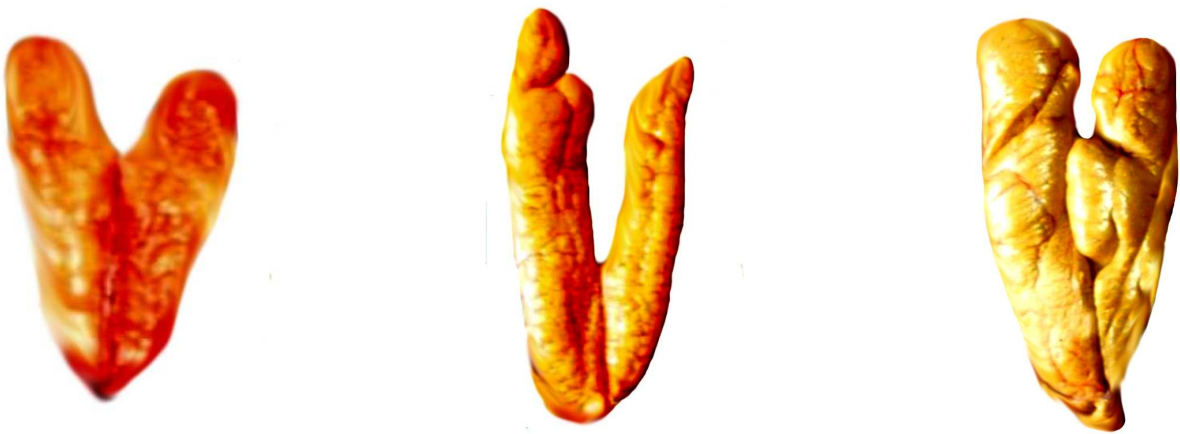

Fig. 1. Virgin/immature ovary present Fig. 2. Ovary present in the Fig. 3. Ovary present in the in the stocking fish. control $\left(D_{1}\right)$ diet fed fish. treated $\left(\mathrm{D}_{2}\right)$ diet fed fish. 


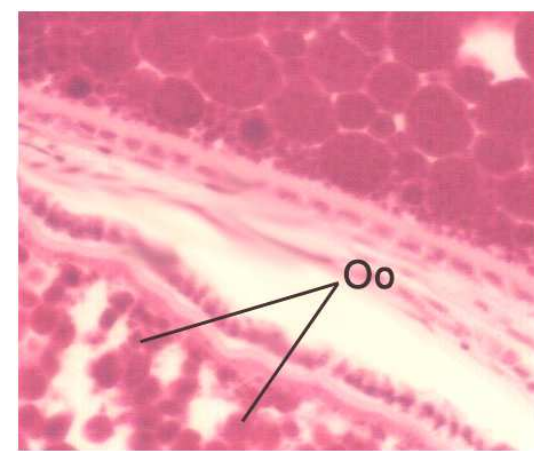

(a)

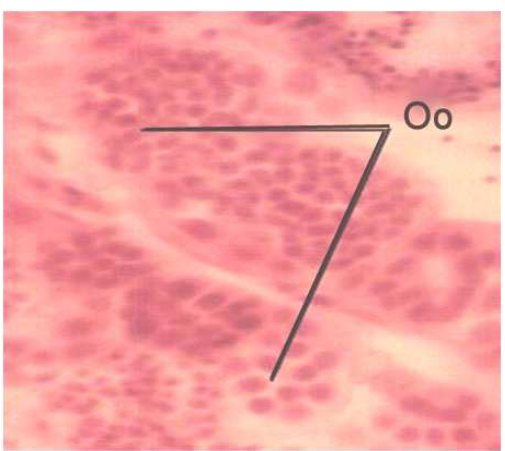

(b)

Fig. 4. Micrograph showing transverse sections of growing oocytes observed in the $D_{2}$ diet (b) fed fish as compared to the control (a) diet fed Labeo rohita; Oo=Oocytes H\&E.

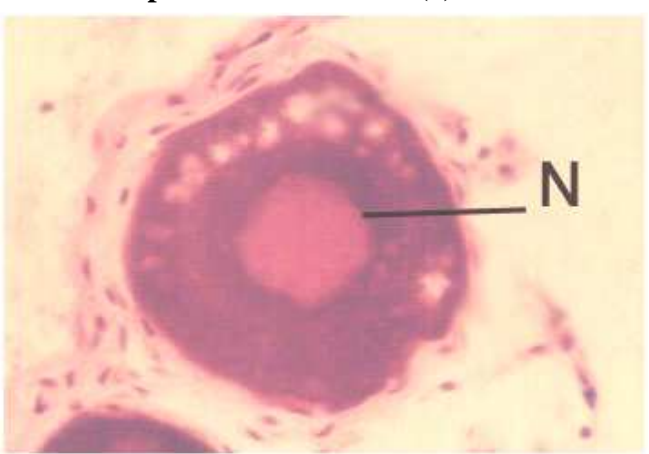

(c)

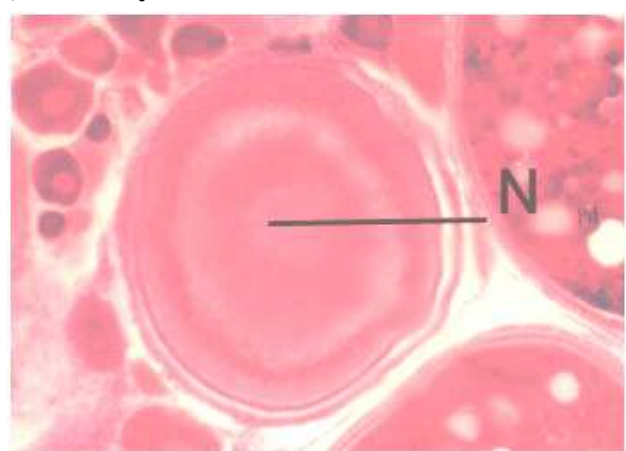

(d)

Fig. 5. Micrograph showing transverse sections of developed nucleus (d) observed in the oocyte of $D_{2}$ diet fed fish as compared to the developing nucleus (c) found in the oocyte of control diet fed fish; $\mathrm{N}=$ Nucleus H\&E.

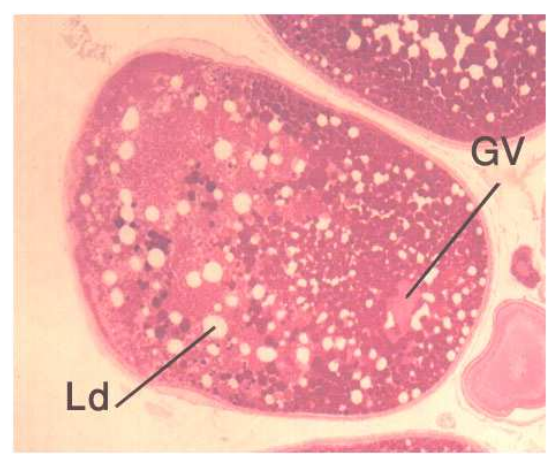

(e)

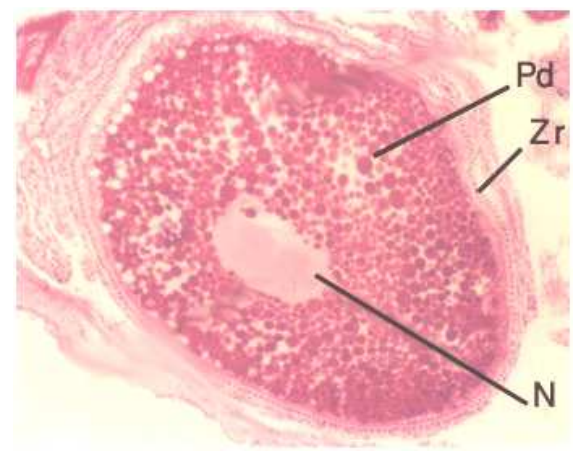

(f)

Fig. 6. Micrograph shows zona radiata $(\mathrm{Zr})$ and protein droplets (Pd) found well developed in the secondary growth phase of $D_{2}$ diet fed fish (f) as compared to the $D_{1}$ diet (control) fed fishin which Granular vesicle (Gv) and various lipid droplets (Ld) can be observed (e) H\&E.

\section{DISCUSSIONS}

Vitamin $\mathrm{C}$ is an indispensable nutrient required to maintain the physiological processes of different animals including fishes (Tolbert 1979).
However, fish depend upon an exogenous source of vitamin $\mathrm{C}$ as they cannot synthesize it due to the absence of the enzyme L-gulonolactone oxidase (Wilson 1973). Diets devoid of vitamin C result in 
prominent deficiency signs and most notable are spinal deformities, particularly scoliosis and lordosis. Often abnormalities of the cartilage of the eye, gill, gill opercula, and fins are observed in ascorbic acid deficient fish, as well as reduced appetite, slow growth, internal and external haemorrhage, fin erosion, and anaemia. In the present study, the average weight and specific growth rate of major carp Labeo rohita increased as the dietary inclusion of vitamin $\mathrm{C}$ increased. The increased growth rates in several fish species fed diets sufficient in vitamin $\mathrm{C}$ are well documented elsewhere (Dabrowski et al. 1990, 1996, Lee et al. 2001). Navarre and Halver (1989) reported that a higher weight gain was observed in rainbow trout fed high dietary AA (500 to $2000 \mathrm{mg} / \mathrm{kg}$ diet). Tewary and Patra (2008) reported that in Labeo rohita maximum growth $(50.88 \pm 0.18)$ was observed in fish fed with $1000 \mathrm{mg} \mathrm{AA} / \mathrm{Kg}$ diet, while the lowest growth $(30.83 \pm 0.12)$ was observed in control diet fed fish.

Oogenesis is a fundamental phase in the reproductive process of organisms. Its comprehension is essential to understand the reproductive biology of species. Moreover, it provides a detailed picture of the reproductive state of females, which permits us to design and improve economimanagement proposals for species of economic importance. Histological studies on oogenesis provide some information, but they present several limitations when applied to vertebrates. Labeo rohita is heterosexual. Its reproductive system consists of an ovary with two lobes, present on each side of the air bladder in body cavity. They were attached with the swim bladder and the length of two lobes was not equal (Figs. 1, 2 and 3). In the immature fish the two lobes are separate, however, as they grow, they unite posteriorly and form a short oviduct that opens to the exterior through gonopore lying above the anus. Externally each ovary was covered with a thin peritoneal membrane and beneath the membrane lies the tunica albugenia which becomes thinner and thinner as the ovary reaches to full maturity.

Histologically, gonadal development in Labeo rohita is group synchronous type. This type, which is found in fish that spawn annually or once in a spawning season, breeders will develop a cluster of vitellogenic oocytes and advance synchronously through further stages of development (oogenesis), whereas the rest of the oocyte population remains arrested and is used for next year's cycle. In Labeo rohita the ova starts development in earnest in March and increase to full and mature size in June. Its spawning, in wild, probably takes place in late June and July, during the local monsoon season. Sex can be recognized in breeding season when abdomen is rounded (called "chhalli" in local language) and vent bulged out and becomes reddish in colour. In the present study also, it seems that ovaries of rohu started increasing in weight and showed histological advancement. The annual reproductive cycle of Labeo rohita female was studied on the basis of gross appearance, and weight of ovaries. Histologically, this was based on oogenesis, size of oocytes, size and behaviour of nucleus, nuclear membrane, number and location of nucleoli, appearance and distribution of yolk vesicles, yolk granules, appearance of oil droplets (if any), final maturation of oocytes in the treated fish as compared to the control diet fed fish. It is clear from the Figs. 1, 2 and 3 that ovaries present in the fish of without treated with vitamin $\mathrm{C}$ were small in size while the size of ovary was comparatively larger in their weight and length. This has been shown for many fish like major carps (Sen et al. 2002, Day et al. 2004, 2005, Bhattacharyya and Maitra 2006). It is known that major carps spawn during the monsoon season when rainfall is at maximum of the year and a casual relation existed between these parameters as was reported by earlier workers (Jhingran 1986, Jhingran and Pullin 1985, Pillay and Kutty 2005). 
However, it has also been shown many times that the size of the oocyte depends on the size of the fish and the larger fish tend to have bigger and higher number of eggs (Fernandez-Delgado and Herrera 1995, Olivia-Paterna et al. 2002, Plaza et al. 2007).

In conclusion, vitamin $\mathrm{C}$ is not only essential for fish growth but is also for the growth of the gonad. Well developed growth of ovary observed in treated diet fed fish as compared to the controlled diet fed fish. The content of vitamin C in oogonia was one and half fold high in treated $\left(D_{2}\right)$ as compared to the control $\left(D_{1}\right)$ diet fed fish. Morphological study reveals that the two lobes of the ovary are separate in the beginning however as they grow, the lobes come together and an oviduct is formed. Well developed nucleus, protein droplets and oocytes were observed in the micrographs of both treated and controlled diet fed fish. Zona radiate observed in fully grown treated fish which plays a role in the vitellogenic process before fertilization, i.e., the microvilli and pore canals and also helps in easier transportation of yolk materials into oocyte. Thus, from these studies it can be said that vitamin $\mathrm{C}$ is essential for oocyte development and overall growth of the fish. Further studies are needed in this connection from various culture systems used in the country.

\section{ACKNOWLEDGEMENTS}

The author is thankful to Prof. Dr. T.C. Nag and Prof. Dr. T.K. Das, Department of Anatomy, All India Institute of Medical Sciences, New Delhi and Mr. Sandeep Arya, who directed in Microscopic image studies. Their kind support and guidance have been of great value in this study.

\section{REFERENCES}

Al-Amoudi, M.M., A.M.N. El-Nakkadi and B.M. El-Nouman. 1992. Evaluation of optimum dietary requirement of vitamin $\mathrm{C}$ for the growth of Oreochromis spilurus fingerlings in water from the Red Sea. Aquaculture 105:165173.

Berka, R. 1986. The Transport of Live Fish: A Review. EIFAC Tech. Paper 48. Food and Agriculture Organization, Rome, UN, pp. 52.

Bhattacharyya, S. and S.K. Maitra. 2006. Environmental correlate of the testicular events in a major carp Catla catla in an annual reproductive cycle. Biol. Rhythm Res. 37:87110.

Dabrowski, K. and S. Hinterleitner. 1989. Simultaneous analysis of ascorbic acid, dehydroascorbic acid and ascorbic sulfate in biological material. Analyst 114:83-87.

Dabrowski, K., K. Matusiewicz, M. Matusiewicz, P.P. Hoppe and J. Ebeling. 1996. Bioavailability of vitamin $\mathrm{C}$ from two ascorbyl monophosphate esters in rainbow trout, Oncorhynchus mykiss (W.). Aquaculture Nutrition 2:3-10.

Dabrowski, K., R. Lackner R. and C. Doblander. 1990. Effect of dietary ascorbate on the concentration of tissue ascorbic acid, dehydroascorbic acid, ascorbic sulfate, and activity of ascorbic sulfate sulfohydrolase in rainbow trout (Oncorhynchus mykiss). Canadian Journal of Fisheries and Aquatic Sciences 47:1518-1525.

Day, R., S. Bhattacharya and S.K. Maitra. 2004. Temporal pattern of ovarian activity in a major carp Catla catla and its possible environmental correlate in an annual cycle. Biol. Rhythm Res. 35:329-353.

Day, R., S. Bhattacharya and S.K. Maitra. 2005. Importance of photoperiods in the regulation of ovarian activities in Indian major carp Catla catla in an annual cycle. J. biol. Rhythm. 20:145-158.

de Vlaming, V. 1983. Oocyte development patterns and hormonal involvements amoung 
teleosts. In: Control Processes in Fish Physiology. (eds.) Rankin, J.C., T.J. Pitcher and R. Duggan. Croom Helm, London, Wiley, New York.

Fernandez-Delgado, C. and M. Herrera. 1995. Age structure, growth and reproduction of Rutilus lemmingii in a intermittent stream in the Guadalquivir river basin, southern Spain. $J$. Fish Biol. 46:371-380.

Fracalossi, D.M., M.E. Allen, D.K. Nichols and O.T. Oftedal. 2001. Oscars, Astronotus ocellatus, have a dietary requirement for vitamin C. Journal of Nutrition 128:17451751.

Gerrits, P.O. 1990. Staining procedures for tissues embedded in 2-Hydroxyethyl methacrylate. Heraeus Kulzer, Netherlands.

Gouillou-Coustans, M.F., P. Bergot and S.J. Kaushik. 1998. Dietary ascorbic acid needs of common carp (Cyprinus carpio) larvae. Aquaculture 161:453-461.

Guraya, S.S. 1986. The cell and molecular biology of fish oogenesis. Monographs in Developmenttal Biology. 18: Karger.

Halver, J.E., L.M. Ashley and R.R. Smith. 1969. Ascorbic acid requirements of coho salmon and rainbow trout. Translations in American Fisheries Society 987:62-71.

Jhingran, V.G. 1986. Aquaculture of Indian major carps. In: Aquaculture of Cyprinids. (eds.) Billard, R. and J. Marcel. Edition Quae, Paris. pp. 335-346.

Jhingran, V.G. and R.S.V. Pullin. 1985. A Hatchery Manual for the Common Chinese and Indian Major Carps. ICLARM, Manila.

Jorgensen, C.B. 1974. Mechanism regulation ovarian cycle in the toad Bufo bufo bufo (L): role of presence of second growth phase oocyte in controlling recruitment from pool of first growth phase oocytes. Gen. Comp. Endocrinol. 23:170-177.
Khoo, K.H. 1979. The histochemistry and endocrine control of vitellogenesis in goldfish ovaries. Can. J. Zool. 57:617-626.

Labh, S.N. and R. Chakrabarti. 2011. Effects of different dietary supplements of vitamin c 1ascorbate-2-triphosphate calcium (LATP-Ca) on growth, tissue vitamin $\mathrm{c}$ and liver ultrastructure of indian major carp mrigal Cirrhinus mrigala $(\mathrm{H})$ during intensive aquaculture. Journal of Theoretical and Experimental Biology, Elias Academic Publishers, 7(4):165-171.

Lee, S.H., T. Oe and I.A. Blair. 2001. Vitamin C induced decomposition of lipid hydroperoxides to endogenous genotoxins. Science 292:2083-2086.

Lim, C. and R.T. Lovell. 1978. Pathology of the vitamin C deficiency syndrome in channel catfish, Ictalurus punctatus. Journal of Nutrition 108:1137-1146.

Lone, K.P., S. Al-Ablani and A. Al-Yakout. 2001. Steroid hormone profile and correlative gonadal histological changes during nature sex reversal of zobaidy kept in tanks and seacages. J. Fish Biol. 58:305-324.

Lone, K.P., S. Al-Ablani and S. Almatar. 2008. Oogenesis, histological gonadal cycle, seasonal variations and spawning season of female silver pomfret (Pampus argenteus, Euphrasen) from the spawning grounds of Kuwait. Pakistan J. Zool. 40:397-407.

Nagahama, Y. 1983. The functional morphology of teleost gonads. In: Fish Physiology. (eds.) Hoae, W.S., D.J. Randall and E.R. Donaldson. Academic Press, New York, IX(A):223-275.

Narimatsu, Y., A. Yamanobe and M. Takahashi. 2007. Reproductive cycle, age and body size at maturity and fecundity of female willow flounder Tanakius kitaharai. Fish. Sci. 73:5562. 
Navarre, O. and J.E. Halver. 1989. Disease resistance and humoral antibody production in rainbow trout fed high levels of vitamin $\mathrm{C}$. Aquaculture 79:207-213.

Olivia-Paterna, F.J., M.M. Torralva and C. Fernandez-Delgado. 2002. Age, growth and reproduction of Cobitis paludica in a seasonal stream. J. Fish Biol. 60:389-404.

Pillay, T.V.R. and M.N. Kutty. 2005. Aquaculture: Principles and Practices. $2^{\text {nd }}$ ed. Blackwell Publishers, London.

Plaza, G., H. Sakaji, H. Honda, Y. Hirota and K. Nashida. 2007. Spawning pattern and type of fecundity in relation to ovarian allometry in the round herring Etrumeus teres. Mar. Biol. 152:1051-1064.

Raven, C.P. 1961. Oogenesis: The storage of developmental information. Pergamon Press, London, New York and Paris.

Sen, U., D. Mukherjee, S.P. Bhattacharyya and D. Mukrerjee. 2002. Seasonal changes in plasma steroid levels in Indian major carp Labeo rohita: Influence of homologous pituitary extract and steroid production and development of oocyte maturational competence. Gen. Comp. Endocrinol. 128:123-134.

Shrestha, T.K. 1980. Rhythm of oocyte maturation and reproductive cycling in a female stone loach, Noemacheilus beavane (Gunther). Intl. J. Acad. 1:19-20.

Tewary, A. and B.C. Patra. 2008. Use of vitamin C as an immunostimulant. Effect on growth, nutritional quality, and immune response of Labeo rohita (H.) Fish Physiology and Biochemistry 34:251-259.

Tokarz, R.R. 1978. Oogonial proliferation, oogenesis, and folliculogenesis in nonmammalian vertebrates. In: The Vertebrate Ovary. (ed.) Jones, R.E. Plenum Press, New York, pp. 145-179.

Tolbert, B.M. 1979. Ascorbic acid metabolism and physiological function. International Journal of Veterinary, Nutrition and Research 19:127142.

Wallace, R.A. 1978. Oocyte growth in nonmammalian vertebrates. In: The Vertebrate Ovary. (ed.) Jones, R.E. Plenum, New York, pp. 469-502.

Wallace, R.A. and K. Selman. 1981. Cellular and dynamic aspects of oocyte growth in teleosts. Amer. Zool. 21:325-343.

West, G. 1990. Method of assessing ovarian development in fishes: a review. Aust. J. Mar. Freshwater Res. 41:199-222.

Wilson, R.P. 1973. Absence of ascorbic acid synthesis in channel catfish, Ictalurus punctatus and blue catfish, Ictalurus furcatus. Comparative Biochemistry and Physiology B 46:635-638.

Yamamoto, K., I. Oota, K. Takano and T. Ishikawa. 1965. Studies on the maturing process of the rainbow trout, Salmo gairdneri irideus. 1. Maturation of the ovary of a oneyear old fish. Bull. Jpn. Soc. Sci. Fish 31:123132. 